\title{
An observational study of acarbose treatment in patients with type 2 diabetes from the Middle East and Morocco
}

This article was published in the following Dove Press journal:

Diabetes, Metabolic Syndrome and Obesity:Targets and Therapy

8 April 2013

Number of times this article has been viewed

\author{
Abdul R Shihabi' \\ Essam M Moussa ${ }^{2}$ \\ Hania Sobierajska ${ }^{3}$ \\ Birgit Schmidt ${ }^{4}$ \\ 'Al Ain Centre, Dubai, United Arab \\ Emirates; ${ }^{2} \mathrm{New}$ Jeddah Hospital, \\ Jeddah, Saudi Arabia; ${ }^{3}$ Etihad Airways \\ Medical Centre, Abu Dhabi, United \\ Arab Emirates; ${ }^{4}$ Bayer Schering \\ Pharma AG, Leverkusen, Germany
}

Correspondence: Abdul Rahman Shihabi I I 3 Al Ain Centre, Mankhool Road, Bur Dubai, Dubai, United Arab Emirates Tel +97 I5 065। 8769

Fax +97 | 435 I 4747

Email shehabi@emirates.net.ae
Background: The prevalence of type 2 diabetes is increasing dramatically in the Middle East and North Africa region. However, there are few trials that have determined the effect of antidiabetic treatment in an observational setting in these countries.

Methods: This was a noninterventional study performed in Morocco in 2006-2007 and in the Middle East in 2005-2006 to observe the efficacy and safety of acarbose in patients with pretreated or untreated type 2 diabetes. Glycemic parameters (fasting blood glucose, one-hour postprandial blood glucose, and $\mathrm{HbA}_{1 \mathrm{c}}$ ) were recorded within a 3-month period. The observation period included an initial visit at the start of acarbose therapy and up to three follow-ups.

Results: Acarbose was effective in reducing glycemic parameters in patients from Morocco $(\mathrm{n}=1082)$ and the Middle East $(\mathrm{n}=1737)$. The mean one-hour postprandial blood glucose decreased by $35.5 \%$ to $165.4 \pm 47.9 \mathrm{mg} / \mathrm{dL}$ in the Middle East and by $35.5 \%$ to $179.0 \pm 49.9 \mathrm{mg} / \mathrm{dL}$ in Morocco. Mean fasting blood glucose decreased by $30.8 \%$ to $126.6 \pm 34.2 \mathrm{mg} / \mathrm{dL}$ (Middle East) and by $34.5 \%$ to $150.6 \pm 47.1 \mathrm{mg} / \mathrm{dL}$ (Morocco). The absolute reduction in $\mathrm{HbA}_{1 \mathrm{c}}$ was $1.3 \%$ in the Middle East (final value $7.4 \%$ ) and $1.0 \%$ in Morocco (final value $7.5 \%$ ). Overall, 107 patients (Middle East) and 26 patients (Morocco) experienced minor drug-related adverse events, which were mainly gastrointestinal. The tolerability of acarbose was rated as very good/ good by $80.8 \%$ in the Middle East and by $68.6 \%$ in Morocco.

Conclusion: This study illustrates the efficacy and safety of acarbose in the treatment of type 2 diabetic patients in an observational setting.

Keywords: type 2 diabetes, acarbose, Glucobay ${ }^{\circledR}$, Glucor ${ }^{\circledR}$, observational, noninterventional

\section{Introduction}

The prevalence of type 2 diabetes and associated cardiovascular disease burden is increasing worldwide. The greatest relative increase is estimated to occur in the Middle East North Africa region, where the number of people aged 20-79 years with diabetes is predicted to increase from 26.6 million in 2010 to 51.7 million in 2030 . ${ }^{1,2}$ At present, six countries in this region are also estimated to be among the world's 10 highest for diabetes prevalence; these include Bahrain, Egypt, Kuwait, Oman, Saudi Arabia, and United Arab Emirates. ${ }^{1,2}$ The prevalence of diabetes in the Middle East North Africa region will be associated with considerable social and economic burden; approximately 280,000 deaths in this region (just over $10 \%$ of all deaths) were estimated to be attributable to diabetes in 2011, and the total annual health care costs are approximately US\$ 10.9 billion. ${ }^{1}$

Given that the change in type 2 diabetes in the Middle East North Africa region is linked to an aging population, socioeconomic changes, and lifestyle factors such 
as increased rates of obesity and smoking, ${ }^{1,3}$ it is important to consider optimal ways, including dietary and pharmacological approaches, to reduce this growing burden. However, despite the growing prevalence of type 2 diabetes, there is a paucity of studies of antidiabetic interventions within these populations. $^{4-6}$

Improved glycemic control, particularly postprandial blood glucose, could reduce adverse cardiovascular outcomes. Postprandial blood glucose has been linked to mortality in a number of epidemiological studies. In the DECODE (Diabetes Epidemiology: Collaborative analysis Of Diagnostic criteria in Europe) study, the hazard ratio for all-cause and cardiovascular mortality was more predictive based on postprandial blood glucose than on fasting blood glucose (1.73 versus 1.21 [all-cause] and 1.40 versus 1.20 [cardiovascular], respectively). ${ }^{7-10}$ Therefore, reduction of postprandial blood glucose could reduce the vascular burden associated with diabetes, and this needs to be demonstrated in clinical practice. The $\alpha$-glucosidase inhibitor, acarbose, has been shown to reduce postprandial blood glucose and cardiovascular events in randomized trials, ${ }^{11-15}$ and provides additional glycemic control in combination with sulfonylureas and biguanides. ${ }^{16,17}$

A recent international, observational study in 14,418 patients with pretreated or untreated type 2 diabetes from countries with a high diabetes burden, such as China, Indonesia, Pakistan, and the Philippines, reported a significant reduction in postprandial blood glucose and $\mathrm{HbA}_{1 \mathrm{c}}$, with an optional extension period up to 2 years. ${ }^{18}$ This is one of the first large-scale studies to demonstrate the effects of acarbose in real-life settings. The aim of this paper is to report the results from this observational study in the Middle East North Africa region (Bahrain, Egypt, Jordan, Kuwait, Lebanon, Libya, Qatar, Saudi Arabia, United Arab Emirates, Yemen, and Morocco).

\section{Materials and methods}

The aim of this prospective, multicenter, observational study was to monitor the efficacy and safety of, and physician satisfaction with, acarbose therapy in patients with type 2 diabetes in a real-life setting. This paper reports the results for patients enrolled from the Middle East (Bahrain, Egypt, Jordan, Kuwait, Lebanon, Libya, Qatar, Saudi Arabia, United Arab Emirates, Yemen), (study identifier GB0401EG) and Morocco (study identifier GB0401MA). The results for the international cohort are reported elsewhere. ${ }^{18}$ Patients were recruited between September 2005 and December 2006 in the Middle East and between September 2006 and June 2007 in Morocco.
The study was performed in accordance with European Medicines Agency guidelines and applicable local laws and regulations. Ethics approval and informed consent were not required, because no additional investigations other than those in regular practice were performed and no patients were allocated systematically to treatment. Inclusion of a patient in the study and subsequent treatment decisions were made by each individual physician.

Eligible patients were defined as males and females with untreated or pretreated type 2 diabetes who were considered suitable for acarbose therapy by their physician. The decision to prescribe acarbose (Glucobay ${ }^{\circledR}$; Glucor ${ }^{\circledR}$ in Morocco, Bayer, Berlin, Germany) was made by the treating physician, and no interventions in the management decisions of the physician were allowed. Patients were assessed at an initial visit (baseline), during which acarbose was prescribed, and at three follow-up clinic visits. The follow-up visits could be scheduled at any time over a 3-month observation period as decided by the treating physician. Patients had to attend at least one follow-up visit, and the final visit was defined as the last follow-up visit recorded by the physician. Acarbose could be used as a replacement for current antidiabetic medication, as an add-on, or both (add-on followed by replacement of at least one pretreatment drug), in pretreated patients. The dose of acarbose could be adjusted during the follow-up visits, and antidiabetic comedication was permitted.

\section{Observation parameters}

Glycemic parameters (fasting blood glucose, one-hour postprandial blood glucose, and $\mathrm{HbA}_{1 \mathrm{c}}$ ) were recorded at baseline and during follow-up visits according to the treating physician's usual procedures, and type 2 diabetes was diagnosed according to local protocols and guidelines. Patient weight was also measured at baseline and follow-up visits. Physician rating of efficacy was recorded on a four-point scale ("very good", "good", "sufficient", "insufficient"). Physician satisfaction with acarbose efficacy was measured using a four-point scale ("very good", "good", "sufficient", "insufficient"), along with the likelihood of continuation of acarbose therapy.

All adverse events that occurred during the observation period were documented and assessed by the physician and recorded on adverse event report forms included in the case report form. An adverse event was defined as any untoward medical occurrence in a patient who received a pharmaceutical product which does not necessarily have a causal relationship with it. The relationship to the pharmaceutical product was determined by the treating physician. An adverse 
drug reaction was defined as any adverse event that was considered to be drug-related. Adverse events were coded using the Medical Dictionary for Regulatory Activities (MedDRA v10.0) and preferred term. The case report forms were screened for any hidden adverse event and followed up with the treating physician where applicable. Overall tolerability of acarbose was assessed by the treating physician using a four-point scale ("very good", "good", "sufficient", "insufficient"), and patient satisfaction with acarbose therapy was documented using a three-point scale ("very satisfied", "satisfied", "not satisfied").

\section{Statistical analysis}

All efficacy analyses were performed on patients who were continuously treated with acarbose and had at least one follow-up visit documented (the per-protocol population), and safety analyses were performed on patients who received at least one dose of acarbose (the intent-to-treat population). Descriptive and exploratory analyses of efficacy, safety, and tolerability outcomes were performed on nonmissing data for each variable at each visit (ie, not using last observation carried forward). Continuous data are presented as the mean \pm standard deviation. The following statistical characteristics of distribution were calculated for numerical data: median, mean, standard deviation, minimum, maximum, and percentiles $1 \%, 5 \%, 25 \%, 75 \%, 95 \%$, and $99 \%$. The change between baseline, each documented follow-up visit, and the final visit are reported for fasting blood glucose, $\mathrm{HbA}_{1 \mathrm{c}}$ and one-hour postprandial blood glucose, and the data are stratified according to factors such as gender, obesity (defined by body mass index), pretreatment or no pretreatment for diabetes, and antidiabetic comedication administered during the observation period. Analyses were performed using SAS for Windows, release 9.1 (SAS Inc, Cary, NC).

\section{Results}

\section{Study population}

A total of 1763 patients from the Middle East and 1085 from Morocco were included in this study. Altogether, 26 patients were excluded from the Middle East cohort due to protocol violations (double entry $[\mathrm{n}=1]$, final visit before study start $[\mathrm{n}=23]$, and no follow-up visits documented $[\mathrm{n}=2]$ ), and three were excluded from the Morocco cohort because of no visits being documented. All efficacy and safety analyses were performed on patients who received at least one dose of acarbose ( $\mathrm{n}=1737$, Middle East; $\mathrm{n}=1082$, Morocco). The baseline characteristics for these patients are summarized in Table 1.
Table I Baseline characteristics of patients from Morocco and the Middle East ${ }^{\mathrm{a}}$

\begin{tabular}{|c|c|c|}
\hline Variable & $\begin{array}{l}\text { Morocco } \\
(n=1082)\end{array}$ & $\begin{array}{l}\text { Middle East } \\
(\mathrm{n}=1737)\end{array}$ \\
\hline Age (years) & $54.7 \pm 11.0$ & $50.0 \pm 10.4$ \\
\hline Age range (years) & $24.0-88.0$ & $15.0-95.0$ \\
\hline Male gender (n [\%]) & $406(37.5)$ & $998(57.5)$ \\
\hline Body mass index $\left(\mathrm{kg} / \mathrm{m}^{2}\right)$ & $27.8 \pm 4.3$ & $29.8 \pm 5.2$ \\
\hline Current smoker (n [\%]) & $87(8.0)$ & $368(21.2)$ \\
\hline Cardiovascular risk factors (n [\%]) & $766(70.8)$ & $1496(86.1)$ \\
\hline Hypertension (n [\%]) & $419(38.7)$ & $776(44.7)$ \\
\hline Concomitant diseases (n [\%]) & $395(36.5)$ & $7 \mid 6(4 \mid .2)$ \\
\hline $\mathrm{HbA}_{\mathrm{Ic}}(\%)$ & $8.5 \pm 1.6$ & $8.67 \pm 1.60$ \\
\hline Fasting blood glucose (mg/dL) & $229.8 \pm 72.6$ & $182.9 \pm 55.8$ \\
\hline $\begin{array}{l}\text { One-hour postprandial blood } \\
\text { glucose }(\mathrm{mg} / \mathrm{dL})\end{array}$ & $277.7 \pm 83.0$ & $256.3 \pm 74.9$ \\
\hline Any antidiabetic agents (n [\%]) & $620(57.3)$ & $132 \mid(76.1)$ \\
\hline$>I(n[\%])$ & $488(78.7)$ & $648(49.1)$ \\
\hline$>2(\mathrm{n}[\%])$ & $122(19.7)$ & $575(43.5)$ \\
\hline$>3(n[\%])$ & $10(1.6)$ & $94(7.1)$ \\
\hline$>4(\mathrm{n}[\%])$ & $0(0)$ & $4(0.3)$ \\
\hline \multicolumn{3}{|l|}{ Duration of treatment ${ }^{c}$ (years) } \\
\hline$<\mathrm{I}(\mathrm{n}[\%])$ & $85(13.7)$ & $196(14.8)$ \\
\hline $\mathrm{I}-5$ (n [\%]) & $279(45.0)$ & $568(43.0)$ \\
\hline$>5-10(\mathrm{n}[\%])$ & $145(23.4)$ & $310(23.5)$ \\
\hline$>10(\mathrm{n}[\%])$ & $81(13.1)$ & $188(14.2)$ \\
\hline
\end{tabular}

Notes: ${ }^{a}$ Plus/minus values are means \pm standard deviation; body mass index (Western standard); 'pretreated patients only (duration of treatment not recorded for all patients).

The mean age and body mass index were comparable between the two populations; however, there was a higher proportion of males in the Middle East population compared with Morocco (57.5\% versus $37.5 \%$, respectively). The Middle East cohort also had more current smokers (21.2\% versus $8.0 \%$ ), and was associated with a higher number of cardiovascular risks $(86.1 \%$ versus $70.8 \%)$. The most common cardiovascular risk factors in the Middle East were hypertension (44.7\%), dyslipidemia (36.2\%), and obesity (35.5\%). In Morocco, the most common cardiovascular risk factors were hypertension $(38.7 \%)$, age (men $>55$ years, women $>65$ years, $26.6 \%$ ), and obesity $(26.3 \%)$. Concomitant diseases were higher in the Middle East compared with Morocco (41.2\% versus 36.5\%); these included cardiac disease $(13.9 \%$ versus $9.1 \%)$, metabolic disease $(9.0 \%$ versus $7.3 \%)$, and vascular disease ( $8.7 \%$ versus $6.7 \%)$.

\section{Observation period}

The number of patients documented for follow-up visits over the 3-month observational period is illustrated in Figure 1. Comparable numbers of patients in the Morocco population attended follow-up visits (93.7\% [visit 1], 81.8\% [visit 2], and 47.7\% [visit 3]) compared with the Middle East 

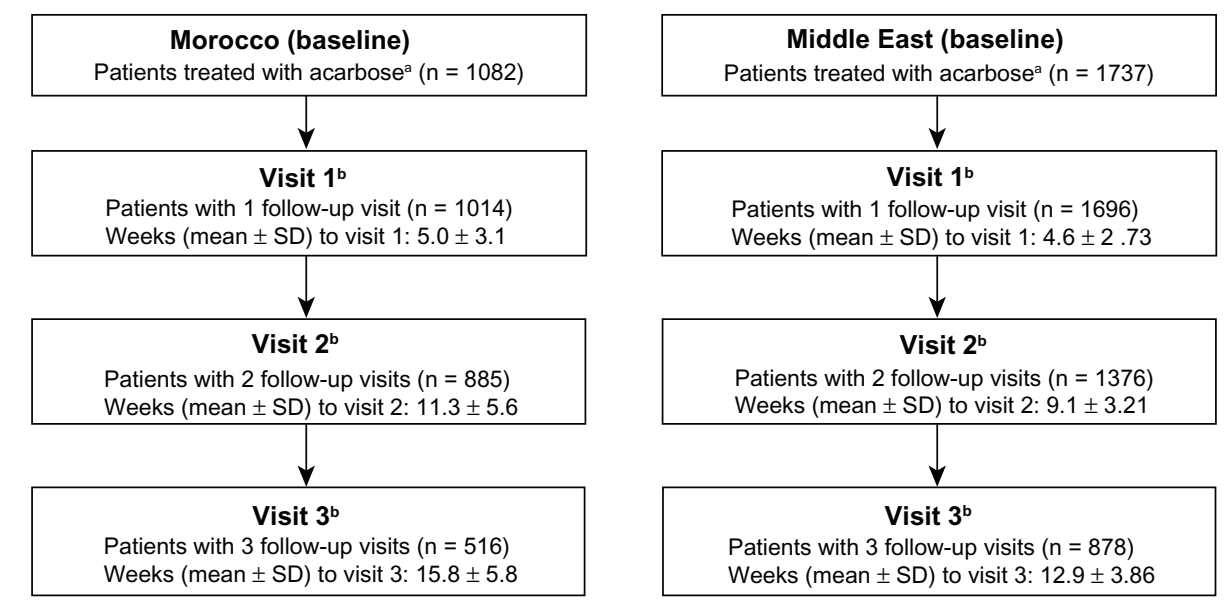

Figure I Patient disposition in the Morocco and Middle East cohorts.

Notes: ancludes pretreated patients in which acarbose could be given as replacement or add-on; bacarbose dose could be adjusted during visits and comedication could be prescribed.

Abbreviation: SD, standard deviation.

(97.6\% [visit 1], 79.2\% [visit 2], and 50.5\% [visit 3]), but the mean duration to follow-up was longer at each visit compared with the Middle East population; the mean duration to visit 3 was 15.8 weeks in Morocco compared with 12.9 weeks in the Middle East.

\section{Antidiabetic medication}

A higher proportion of patients in the Middle East had antidiabetic medications prescribed at baseline $(76.1 \%$ versus $57.3 \%$ ), which could explain why the fasting blood glucose and one-hour postprandial blood glucose were both lower at baseline compared with the Morocco population. The most commonly used medications in the Middle East and Morocco were sulfonylureas (52.6\% versus $42.1 \%$ ), biguanides (40.4\% versus $21.2 \%$ ), and insulin and its analogs (13.0\% versus $5.1 \%)$.

Acarbose was prescribed as add-on therapy for most patients in the Middle East $(82.5 \% ; n=1090 / 1321)$ and Morocco (79.0\%; $n=490 / 620)$. Acarbose was used as replacement therapy for $4.9 \%(n=65 / 1321)$ of patients in the Middle East and 13.5\% $(n=84 / 620)$ in Morocco, and acarbose was used as replacement and add-on treatment in $12.6 \%(n=166 / 1321)$ of patients in the Middle East and in $7.1 \%(n=44 / 620)$ of patients in Morocco. Biguanides were the most commonly replaced drug in the Middle East (54.5\%) compared with sulfonylureas in Morocco (65.6\%). The main reasons for replacement were insufficient efficacy $(59.3 \%$ [Middle East] and 55.5\% [Morocco]) followed by side effects (35.5\% versus $21.1 \%$ ). A total of $1354(78.0 \%)$ patients in the Middle East and 612 (56.6\%) in Morocco received antidiabetic comedication during the observational period.
At the start of acarbose therapy, the mean daily dosage used in the Middle East population was $100.2 \pm 53.2 \mathrm{mg}$ (range 50-300 mg), which increased to $148.6 \pm 76.1 \mathrm{mg}$ (range 25-300 mg) at visit 3. In the course of therapy, $41.0 \%$ of the Middle East patients remained on the same dose, $36.2 \%$ had one dose adjustment, 9.1\% had two dose adjustments, $0.7 \%$ had three dose adjustments, and data on dose adjustments were missing for $13.1 \%$ of patients. In comparison, the mean daily dosage used in the Morocco patients at the start of therapy was $124.8 \pm 59.9 \mathrm{mg}$ (range 50-450 mg), which increased to $172.3 \pm 83.3 \mathrm{mg}$ (range $50-300 \mathrm{mg}$ ) at visit 3 . One dose adjustment was made in $24.8 \%$ of the Morocco participants, two dose adjustments were made in $9.4 \%$, three dose adjustments were made in $1.2 \%$ of patients, $47.5 \%$ remained on the same dose, and dose adjustments were not recorded for $17.1 \%$ of patients.

\section{Effect of acarbose therapy on glycemic parameters}

During the observation period, there was a decrease in onehour postprandial blood glucose, fasting blood glucose, and $\mathrm{HbA}_{1 \mathrm{c}}$ following the administration of acarbose in previously untreated patients or as replacement or add-on in pretreated patients. The overall mean one-hour postprandial blood glucose decreased from $256.3 \pm 74.9 \mathrm{mg} / \mathrm{dL}$ at baseline to $165.4 \pm 47.9 \mathrm{mg} / \mathrm{dL}$ at final visit in the Middle East and from $277.7 \pm 83.0 \mathrm{mg} / \mathrm{dL}$ to $179.0 \pm 49.9 \mathrm{mg} / \mathrm{dL}$ in Morocco (Figure 2A). The mean change in one-hour postprandial blood glucose was proportional to the baseline values. The mean change in one-hour postprandial blood glucose was $37.3 \mathrm{mg} / \mathrm{dL}$ in patients with a baseline postprandial blood 


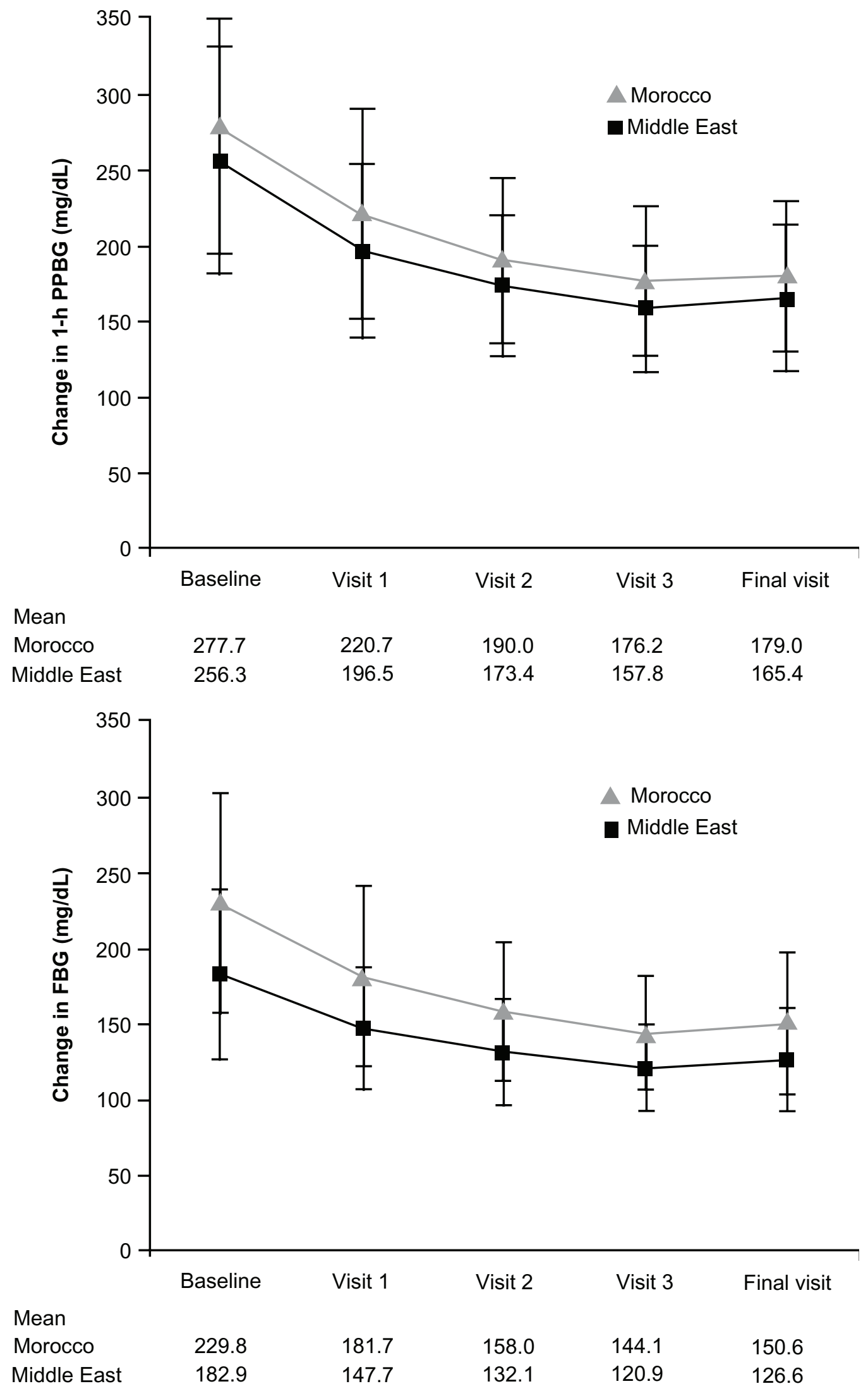

Figure 2 Effect of acarbose treatment on mean \pm standard deviation (shown as vertical bars) change over time in (A) one-hour postprandial blood glucose (mg/dL) and (B) fasting blood glucose $(\mathrm{mg} / \mathrm{dL})$ in patients from Morocco and the Middle East.

Abbreviations: PPBG, postprandial blood glucose; FBG, fasting blood glucose. 
glucose in the range of 151-200 $\mathrm{mg} / \mathrm{dL}$ compared with $215.4 \mathrm{mg} / \mathrm{dL}$ for those with a baseline postprandial blood glucose in the range of $401-450 \mathrm{mg} / \mathrm{dL}$ in Morocco; the corresponding values in the Middle East were $40.5 \mathrm{mg} / \mathrm{dL}$ and $204.1 \mathrm{mg} / \mathrm{dL}$, respectively (Table 2). Acarbose was equally effective in males and females, and in pretreated and previously untreated patients; the final mean one-hour postprandial blood glucose was $169.8 \pm 49.0 \mathrm{mg} / \mathrm{dL}$ in pretreated patients compared with $151.6 \pm 41.5 \mathrm{mg} / \mathrm{dL}$ in patients receiving no antidiabetic medication at study entry in the Middle East population (Table 3). In the Morocco population, the stratified-by-weight analysis showed initial one-hour postprandial blood glucose levels of $262.8 \mathrm{mg} / \mathrm{dL}$ for normal weight patients, $279.6 \mathrm{mg} / \mathrm{dL}$ for overweight patients, and $286.1 \mathrm{mg} / \mathrm{dL}$ for obese individuals. At the end of the observation phase, these values had decreased to 173.2, 178.8 , and $182.8 \mathrm{mg} / \mathrm{dL}$, respectively.

The mean fasting blood glucose decreased from $182.9 \pm 55.8 \mathrm{mg} / \mathrm{dL}$ to $126.6 \pm 34.2 \mathrm{mg} / \mathrm{dL}$ in the Middle East and from $229.8 \pm 72.6 \mathrm{mg} / \mathrm{dL}$ to $150.6 \pm 47.1 \mathrm{mg} / \mathrm{dL}$ in Morocco following acarbose therapy (Figure 2B). The mean change in fasting blood glucose was proportional to the baseline values in both countries (Table 2). There was also a reduction in fasting blood glucose in patients receiving acarbose monotherapy (mean fasting blood glucose decreased from $171.1 \mathrm{mg} / \mathrm{dL}$ to $113.2 \mathrm{mg} / \mathrm{dL}$ in the Middle East cohort) and in those receiving antidiabetic comedication (mean fasting blood glucose decreased from $186.4 \mathrm{mg} / \mathrm{dL}$ to $130.6 \mathrm{mg} / \mathrm{dL}$ in the Middle East cohort). Acarbose was also effective in obese patients. These patients had the highest fasting blood glucose at baseline $(238.9 \mathrm{mg} / \mathrm{dL}$ versus $226.7 \mathrm{mg} / \mathrm{dL}$ [overweight] and $225.5 \mathrm{mg} / \mathrm{dL}$ [normal weight]); the mean fasting blood glucose decreased from $238.9 \mathrm{mg} / \mathrm{dL}$ to $152.5 \mathrm{mg} / \mathrm{dL}$ in obese patients in the Morocco cohort (Table 3 ).

The mean reduction in $\mathrm{HbA}_{1 \mathrm{c}}$ is shown in Figure 3. In Morocco, mean $\mathrm{HbA}_{1 \mathrm{c}}$ reduced from $8.5 \% \pm 1.6 \%$ (baseline) to $7.5 \% \pm 1.2 \%$ (final visit), which is an absolute reduction of $1.0 \%$ and a relative reduction of $10.6 \%$. Acarbose was effective in males and females; the mean $\mathrm{HbA}_{1 \mathrm{c}}$ at final visit was $7.6 \% \pm 1.2 \%$ in males and $7.5 \% \pm 1.1 \%$ in females. In the Middle East, the mean $\mathrm{HbA}_{1 \mathrm{c}}$ was $8.7 \% \pm 1.6 \%$ at baseline and $7.4 \% \pm 1.26 \%$ at the final visit, which is an absolute reduction of $1.3 \%$ and a relative reduction of $13.6 \%$. The mean at the final visit was $7.37 \% \pm 1.2 \%$ for males and $7.49 \% \pm 1.3 \%$ for females.

There was a slight reduction in weight in both countries. Mean body weight decreased from $83.7 \pm 15.5 \mathrm{~kg}$ to $82.0 \pm 14.6 \mathrm{~kg}$ in the Middle East and from $76.2 \pm 11.9 \mathrm{~kg}$ to $74.7 \pm 11.0 \mathrm{~kg}$ in Morocco. In patients from the Middle East using antidiabetic comedication, mean weight decreased from $83.7 \pm 15.5 \mathrm{~kg}$ to $82.2 \pm 14.7 \mathrm{~kg}$.

Physicians in the Middle East rated the efficacy of acarbose as "very good" or "good" for $83.1 \%$ of patients $(0.9 \%$ responses missing, Table 4). The majority (89.9\%) of physicians in the Middle East intended to continue their patient on acarbose treatment ( $6 \%$ missing responses). In Morocco, physicians assessed acarbose efficacy as "very good" or "good" in $69.2 \%$ of patients (13.6\% missing responses), and continuation was expected in $75.8 \%$ of patients $(18.4 \%$ missing responses).

\section{Tolerability and safety}

Among patients from the Middle East, 180 adverse events were reported in $121(7.0 \%)$ patients; 159 adverse events in 107 patients $(6.2 \%)$ were considered drug-related (ie, adverse drug reactions), and primarily affected the gastrointestinal system (Table 5). Corresponding rates in the Moroccan population were as follows: 48 adverse events in 34 patients (3.1\%) and 39 adverse events in 26 patients $(2.4 \%)$ were considered drug-related (adverse drug reactions). There were no serious adverse events or serious adverse drug reactions in either population.

Overall tolerability was rated by physicians as "very good" or "good" in $80.8 \%$ of all patients in the Middle East

Table 2 Effect of acarbose treatment on mean change $(\Delta)$ in fasting blood glucose and one-hour PPBG from baseline to final visit in the Morocco and Middle East cohorts

\begin{tabular}{|c|c|c|c|c|c|c|c|c|c|c|}
\hline $\mathrm{mg} / \mathrm{dL}$ & $\leq 100$ & $101-150$ & $|5|-200$ & $20 I-250$ & $25 I-300$ & $301-350$ & $35 I-400$ & $40 I-450$ & $>450$ & Total \\
\hline \multicolumn{11}{|l|}{ Morocco } \\
\hline Mean $\Delta$ in FBG & -12.5 & 21.4 & 44.9 & 73.8 & 113.0 & 142.6 & 161.7 & 222.6 & 308.1 & 80.3 \\
\hline Mean $\Delta$ in one-hour PPBG & -52.5 & -1.7 & 37.3 & 64.3 & 95.9 & 141.9 & 167.2 & 215.4 & 263.9 & 102.5 \\
\hline \multicolumn{11}{|l|}{ Middle East } \\
\hline Mean $\Delta$ in FBG & -9.1 & 22.1 & 52.8 & 80.9 & 110.8 & 142.0 & 202.3 & 283.7 & NA & 55.7 \\
\hline Mean $\Delta$ in one-hour PPBG & -82.8 & 16.0 & 40.5 & 65.4 & 107.1 & 139.5 & 184.5 & 204.1 & 251.8 & 91.6 \\
\hline
\end{tabular}

Note: Data are stratified according to baseline values.

Abbreviations: FBG, fasting blood glucose; NA, not assessed; PPBG, postprandial blood glucose. 
Table 3 Mean \pm standard deviation total change in FBG and one-hour PPBG from baseline to final visit in the Morocco and Middle East cohorts according to subgroups treated with acarbose

\begin{tabular}{|c|c|c|c|c|c|c|c|c|}
\hline & \multicolumn{4}{|c|}{ Middle East $(n=1737)$} & \multicolumn{4}{|c|}{ Morocco $(n=1082)$} \\
\hline & \multicolumn{2}{|c|}{ FBG (mg/dL) } & \multicolumn{2}{|c|}{ One-hour PPBG (mg/dL) } & \multicolumn{2}{|c|}{ FBG (mg/dL) } & \multicolumn{2}{|c|}{ One-hour PPBG (mg/dL) } \\
\hline & Baseline & Final visit & Baseline & Final visit & Baseline & Final visit & Baseline & Final visit \\
\hline Male & $\begin{array}{l}|8| . \mid \pm 55.0 \\
(n=968)\end{array}$ & $\begin{array}{l}\mid 25.9 \pm 33.1 \\
(n=917)\end{array}$ & $\begin{array}{l}254.4 \pm 74.8 \\
(n=925)\end{array}$ & $\begin{array}{l}165.2 \pm 46.8 \\
(n=905)\end{array}$ & $\begin{array}{l}227.3 \pm 71.3 \\
(n=400)\end{array}$ & $\begin{array}{l}|46.7 \pm 4| .8 \\
(n=380)\end{array}$ & $\begin{array}{l}276.1 \pm 85.3 \\
(n=291)\end{array}$ & $\begin{array}{l}179.5 \pm 54.3 \\
(n=284)\end{array}$ \\
\hline Female & $\begin{array}{l}184.5 \pm 56.4 \\
(n=650)\end{array}$ & $\begin{array}{l}126.9 \pm 34.3 \\
(n=617)\end{array}$ & $\begin{array}{l}257.2 \pm 74.8 \\
(n=608)\end{array}$ & $\begin{array}{l}165.0 \pm 49.0 \\
(n=612)\end{array}$ & $\begin{array}{l}230.7 \pm 72.6 \\
(n=640)\end{array}$ & $\begin{array}{l}151.9 \pm 44.7 \\
(n=592)\end{array}$ & $\begin{array}{l}278.3 \pm 80.0 \\
(n=444)\end{array}$ & $\begin{array}{l}178.6 \pm 47.0 \\
(n=440)\end{array}$ \\
\hline Obese & $\begin{array}{l}186.6 \pm 54.9 \\
(n=600)\end{array}$ & $\begin{array}{l}126.2 \pm 33.0 \\
(n=579)\end{array}$ & $\begin{array}{l}263.1 \pm 70.3 \\
(n=567)\end{array}$ & $\begin{array}{l}166.5 \pm 50.6 \\
(n=569)\end{array}$ & $\begin{array}{l}238.9 \pm 69.7 \\
(n=28 I)\end{array}$ & $\begin{array}{l}\mid 52.5 \pm 40.5 \\
(n=27 \mid)\end{array}$ & $\begin{array}{l}286.1 \pm 82.5 \\
(n=207)\end{array}$ & $\begin{array}{l}182.8 \pm 48.8 \\
(n=214)\end{array}$ \\
\hline Overweight & $\begin{array}{l}178.3 \pm 53.1 \\
(n=594)\end{array}$ & $\begin{array}{l}125.7 \pm 32.9 \\
(n=572)\end{array}$ & $\begin{array}{l}248.8 \pm 75.5 \\
(n=572)\end{array}$ & $\begin{array}{l}|63.7 \pm 4| .5 \\
(n=554)\end{array}$ & $\begin{array}{l}226.7 \pm 67.2 \\
(n=437)\end{array}$ & $\begin{array}{l}148.5 \pm 40.2 \\
(n=4 \mid 0)\end{array}$ & $\begin{array}{l}279.6 \pm 80.4 \\
(n=322)\end{array}$ & $\begin{array}{l}178.8 \pm 46.2 \\
(n=3 \mid 1)\end{array}$ \\
\hline Normal weight & $\begin{array}{l}178.5 \pm 56.6 \\
(n=235)\end{array}$ & $\begin{array}{l}128.8 \pm 37.8 \\
(n=227)\end{array}$ & $\begin{array}{l}246.2 \pm 80.1 \\
(n=214)\end{array}$ & $\begin{array}{l}170.0 \pm 56.1 \\
(n=222)\end{array}$ & $\begin{array}{l}225.5 \pm 82.6 \\
(n=256)\end{array}$ & $\begin{array}{l}\mid 50.3 \pm 60.4 \\
(n=24 \mid)\end{array}$ & $\begin{array}{l}262.8 \pm 85.2 \\
(n=173)\end{array}$ & $\begin{array}{l}173.2 \pm 52.3 \\
(n=174)\end{array}$ \\
\hline With pretreatment & $\begin{array}{l}|84 .| \pm 56.2 \\
(n=\mid 256)\end{array}$ & $\begin{array}{l}130.0 \pm 35.4 \\
(n=\mid 193)\end{array}$ & $\begin{array}{l}258.7 \pm 76.0 \\
(n=1205)\end{array}$ & $\begin{array}{l}169.8 \pm 49.0 \\
(n=\mid 188)\end{array}$ & $\begin{array}{l}232.5 \pm 69.9 \\
(n=613)\end{array}$ & $\begin{array}{l}154.5 \pm 44.5 \\
(n=577)\end{array}$ & $\begin{array}{l}278.6 \pm 78.1 \\
(n=442)\end{array}$ & $\begin{array}{l}182.4 \pm 50.5 \\
(n=427)\end{array}$ \\
\hline Without pretreatment & $\begin{array}{l}179.2 \pm 54.3 \\
(n=4 \mid 3)\end{array}$ & $\begin{array}{l}116.0 \pm 27.9 \\
(n=389)\end{array}$ & $\begin{array}{l}248.6 \pm 70.7 \\
(n=379)\end{array}$ & $\begin{array}{l}|5| .6 \pm 4 \mid .5 \\
(n=38 \mid)\end{array}$ & $\begin{array}{l}226.1 \pm 75.9 \\
(n=455)\end{array}$ & $\begin{array}{l}145.4 \pm 50.2 \\
(n=423)\end{array}$ & $\begin{array}{l}276.4 \pm 89.4 \\
(n=315)\end{array}$ & $\begin{array}{l}174.4 \pm 48.7 \\
(n=322)\end{array}$ \\
\hline $\begin{array}{l}\text { With antidiabetic } \\
\text { comedication }\end{array}$ & $\begin{array}{l}186.4 \pm 57.8 \\
(n=1290)\end{array}$ & $\begin{array}{l}130.6 \pm 36.3 \\
(n=1220)\end{array}$ & $\begin{array}{l}262.3 \pm 77.3 \\
(n=1237)\end{array}$ & $\begin{array}{l}170.2 \pm 50.4 \\
(n=\mid 226)\end{array}$ & $\begin{array}{l}241.2 \pm 75.8 \\
(n=605)\end{array}$ & $\begin{array}{l}156.9 \pm 52.2 \\
(n=572)\end{array}$ & $\begin{array}{l}286.4 \pm 83.5 \\
(n=426)\end{array}$ & $\begin{array}{l}182.6 \pm 52.0 \\
(n=42 \mid)\end{array}$ \\
\hline $\begin{array}{l}\text { Without antidiabetic } \\
\text { comedication }\end{array}$ & $\begin{array}{l}|7| . \mid \pm 46.3 \\
(n=379)\end{array}$ & $\begin{array}{l}113.2 \pm 21.3 \\
(n=362)\end{array}$ & $\begin{array}{l}234.6 \pm 60.8 \\
(n=347)\end{array}$ & $\begin{array}{l}148.2 \pm 32.5 \\
(n=343)\end{array}$ & $\begin{array}{l}214.8 \pm 65.2 \\
(n=463)\end{array}$ & $\begin{array}{l}142.2 \pm 37.9 \\
(n=428)\end{array}$ & $\begin{array}{l}266.5 \pm 8 I .1 \\
(n=33 I)\end{array}$ & $\begin{array}{l}174.2 \pm 46.6 \\
(n=328)\end{array}$ \\
\hline
\end{tabular}

Abbreviations: FBG, fasting blood glucose; PPBG, postprandial blood glucose.

population $(2.3 \%$ responses missing) and in $68.6 \%$ of the Morocco group (with 16.6\% responses missing, Table 4). Physician ratings of tolerability in the Middle East population were higher for previously untreated patients versus their pretreated counterparts $(87.7 \%$ versus $78.6 \%$ rated "very good" or "good") and for those receiving acarbose monotherapy versus acarbose in combination treatment (88.3\% versus $78.7 \%$ ). Tolerability did not differ by age group or gender. In the Morocco population, age, pretreatment and comedication did not affect ratings, but a slightly higher rating was

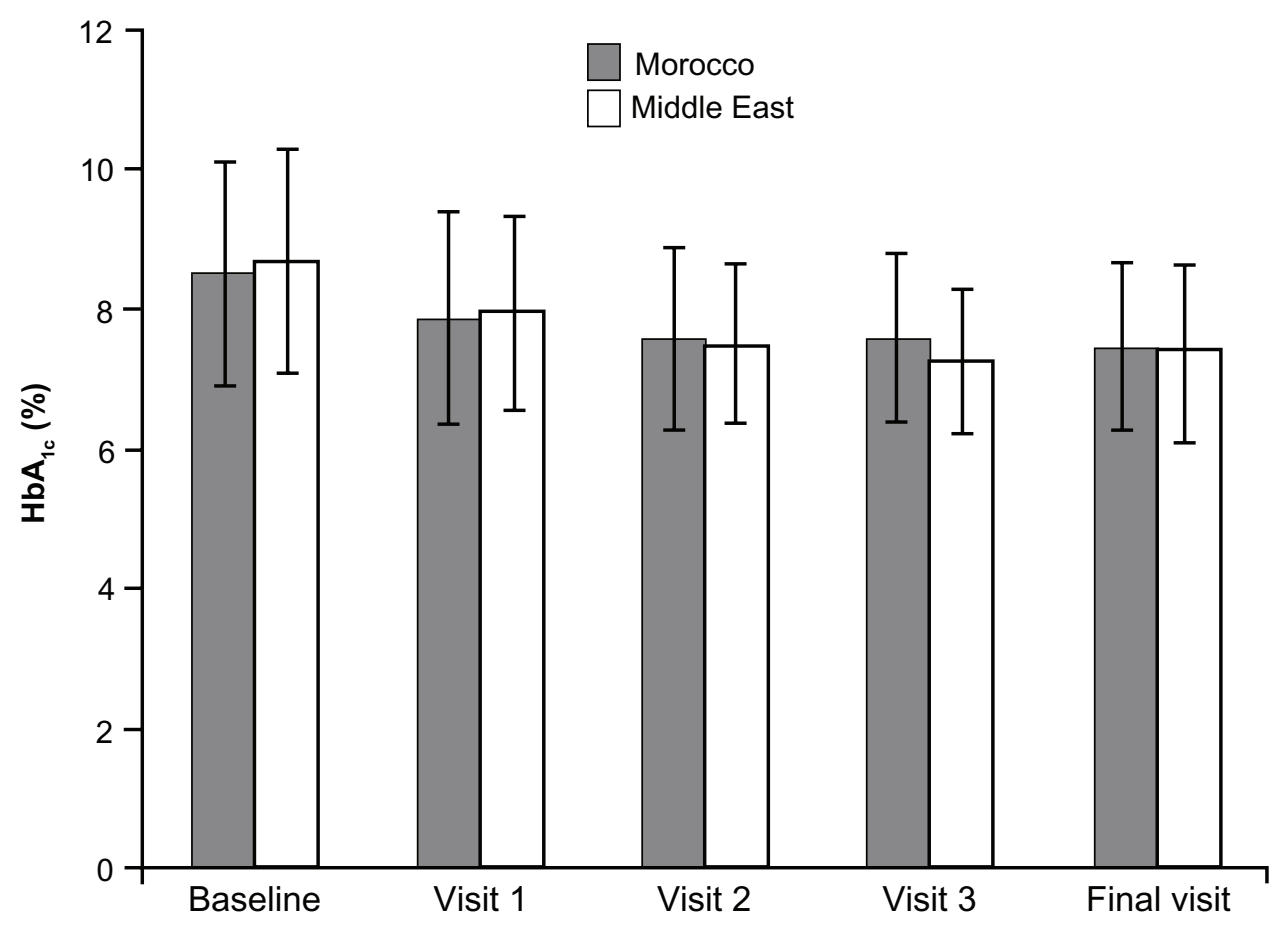

Figure 3 Effect of acarbose treatment on $\mathrm{HbA}_{\mathrm{lc}}$ (mean \pm standard deviation, shown as vertical bars) in patients from Morocco and the Middle East. 
Table 4 Physician satisfaction, $n(\%)$ with (A) acarbose efficacy and (B) overall tolerability assessment

\begin{tabular}{|c|c|c|c|c|}
\hline & Very good & Good & Sufficient & Insufficient \\
\hline \multicolumn{5}{|l|}{ (A) Efficacy } \\
\hline \multicolumn{5}{|l|}{ Morocco } \\
\hline All patients $(n=1082)$ & $321(29.7)$ & $427(39.5)$ & $110(10.2)$ & $77(7.1)$ \\
\hline With pretreatment ${ }^{a}(n=620)$ & I54 (24.8) & $273(44.0)$ & $73(11.8)$ & $5 \mid(8.2)$ \\
\hline Without pretreatment $t^{a}(n=462)$ & $167(36.1)$ & $154(33.3)$ & $37(8.0)$ & $26(5.6)$ \\
\hline \multicolumn{5}{|l|}{ Middle East } \\
\hline All patients $(n=1737)$ & $853(49.1)$ & $590(34.0)$ & $205(11.8)$ & $74(4.3)$ \\
\hline With pretreatment ${ }^{\mathrm{a}}(\mathrm{n}=|32|)$ & $604(45.7)$ & $477(36.1)$ & $17 \mid(12.9)$ & $57(4.3)$ \\
\hline Without pretreatment ${ }^{a}(n=416)$ & $249(59.9)$ & $113(27.2)$ & $34(8.2)$ & $17(4.1)$ \\
\hline \multicolumn{5}{|l|}{ (B) Overall tolerability } \\
\hline \multicolumn{5}{|l|}{ Morocco } \\
\hline All patients $(\mathrm{n}=1082)$ & $301(27.8)$ & $44 \mid(40.8)$ & $|2|(\mid I .2)$ & $39(3.6)$ \\
\hline With pretreatment ${ }^{\mathrm{a}}(\mathrm{n}=620)$ & $160(25.8)$ & $269(43.4)$ & $83(13.4)$ & $21(3.4)$ \\
\hline Without pretreatment ${ }^{\mathrm{a}}(\mathrm{n}=462)$ & $|4|(30.5)$ & $172(37.2)$ & $38(8.2)$ & $18(3.9)$ \\
\hline \multicolumn{5}{|l|}{ Middle East } \\
\hline All patients $(n=1737)$ & $743(42.8)$ & $660(38.0)$ & $249(14.3)$ & $45(2.6)$ \\
\hline With pretreatment ${ }^{\mathrm{a}}(\mathrm{n}=|32|)$ & $524(39.7)$ & $514(38.9)$ & $213(16.1)$ & $35(2.6)$ \\
\hline Without pretreatment ${ }^{\mathrm{a}}(\mathrm{n}=416)$ & $219(52.6)$ & $146(35.1)$ & $36(8.7)$ & $10(2.4)$ \\
\hline
\end{tabular}

Note: ${ }^{\mathrm{A} A n y}$ antidiabetic treatment recorded at baseline.

seen with males versus females $(73.2 \%$ versus $65.7 \%$ rated "very good" or "good") and $<$ two versus $\geq$ two concomitant diseases $(69.3 \%$ versus $63.7 \%)$.

Similar findings were observed in the patient satisfaction assessments. Overall, $90.3 \%$ of patients in the Middle East were either "very satisfied" or "satisfied" with acarbose therapy. In Morocco, a total of $73.3 \%$ patients were "very satisfied" or "satisfied" with acarbose therapy.

\section{Discussion}

This was one of the first large-scale studies to demonstrate the efficacy, safety, and tolerability of acarbose in a real-life setting in patients with type 2 diabetes from the Middle East and North Africa, a region with a growing diabetes pandemic. The study showed that acarbose was effective in reducing all glycemic parameters measured.

Table 5 Incidence ( $\geq 1.0 \%$ ) of adverse events and adverse drug reactions in patients from Morocco and the Middle East treated with acarbose

\begin{tabular}{|c|c|c|c|c|}
\hline \multirow[t]{2}{*}{ n (\%) } & \multicolumn{2}{|c|}{ Morocco $(n=1082)$} & \multicolumn{2}{|c|}{ Middle East $(n=1737)$} \\
\hline & $\mathrm{AE}$ & ADR & $\mathbf{A E}$ & ADR \\
\hline Any AE & $34(3.1)$ & $26(2.4)$ & $12 \mid(7.0)$ & $107(6.2)$ \\
\hline $\begin{array}{l}\text { Gastrointestinal } \\
\text { disorders }\end{array}$ & $31(2.9)$ & $23(2.1)$ & $114(6.6)$ & $103(5.9)$ \\
\hline $\begin{array}{l}\text { Abdominal } \\
\text { distension }\end{array}$ & $2(0.2)$ & $\mathrm{I}(0 . \mathrm{I})$ & $28(1.6)$ & $26(1.5)$ \\
\hline Diarrhea & II (I.0) & $9(0.8)$ & $20(1.2)$ & $18(1.0)$ \\
\hline Flatulence & $10(0.9)$ & $7(0.7)$ & $66(3.8)$ & $57(3.3)$ \\
\hline
\end{tabular}

Abbreviations: $A D R$, adverse drug reaction; $A E$, adverse event.
It was interesting to note that the populations from Morocco and the Middle East had very low levels of glycemic control at study entry compared with the overall population (reported elsewhere) ${ }^{18}$ despite $57.3 \%$ in Morocco and $76.1 \%$ in the Middle East using antidiabetic agents at baseline. The Morocco and Middle East populations also had a slightly higher body mass index compared with the overall group (the mean body mass index was $26.4 \mathrm{~kg} / \mathrm{m}^{2}$ ), but the reduction in body weight over the observation period in the Middle East and Morocco was higher than that in the main study (1.7 [Middle East] versus 1.5 [Morocco] versus $1.1 \mathrm{~kg}$ [main study]). Patients in the Middle East and Morocco also had a considerable number of cardiovascular risk factors, most notably hypertension. A matched-cohort observation study in Europe, which included patients with type 2 diabetes with or without cardiovascular disease, showed that patients with cardiovascular disease had low glycemic control compared to those without cardiovascular disease..$^{19}$ The patients from Morocco and the Middle East had a high number of cardiovascular risk factors ( $70.8 \%$ and $86.1 \%$, respectively), and approximately $40 \%$ had hypertension, which suggests they would have low glycemic control and could be difficult to treat. This was indicated by the high baseline values for fasting blood glucose and one-hour postprandial blood glucose, despite the high use of antidiabetic medications.

In the current study, glycemic control was largely reduced to within the range recommended by the American Diabetes Association (fasting blood glucose 70-130 mg/dL,1-2-hour postprandial blood glucose $\left.<180 \mathrm{mg} / \mathrm{dL}, \mathrm{HbA}_{1 \mathrm{c}}<7.0 \%\right){ }^{20}$ 
However, the duration of the study was not long enough to assess fully the change in $\mathrm{HbA}_{1 \mathrm{c}}$. In the original study, in which certain patients were followed for up to 2 years, $\mathrm{HbA}_{1 \mathrm{c}}$ levels reduced significantly to $6.7 \% .^{18}$

It is possible that glycemic control could have been improved in the Middle East and Morocco cohorts. Acarbose was used as an add-on in $82.5 \%$ of patients in the Middle East and in $79.0 \%$ of patients in Morocco (versus $84.5 \%$ of patients in the main study). Similar to the main study, there was an increase in acarbose dose over the study period, as would be expected given that a "start low, go slow" titration is recommended to maximize tolerability, and minimize the risk of gastrointestinal side effects. ${ }^{21,22}$ In the main study, the mean starting dose was $115.6 \mathrm{mg}$, which increased to $139.4 \mathrm{mg}$ at study end. ${ }^{18}$ In the Middle East, the daily dose was $100.2 \mathrm{mg}$ initially and this increased to $148.6 \mathrm{mg} ; 41.0 \%$ remained on the same dose. In Morocco, the initial daily dose was $124.8 \mathrm{mg}$, which increased to $172.3 \mathrm{mg}$, and $47.5 \%$ remained on the same dose. However, the optimal dose of acarbose is $300 \mathrm{mg}$ daily, which indicates that the dose could have been increased.

There was a low incidence of drug-related adverse events in Morocco (2.4\% of patients) and in the Middle East ( $6.16 \%$ of patients); these were minor gastrointestinal side effects and consistent with previous studies. ${ }^{11-14,23-25} \mathrm{~A}$ previous observational study in 27,803 patients reported flatulence in $13.7 \%$ and diarrhea in $2.2 \%{ }^{26}$ In a study of 10,462 patients in China, 19\% reported flatulence and 3.2\% reported diarrhea. ${ }^{27}$ These findings suggest that acarbose was well tolerated in the Middle East and Morocco cohorts. This was also reflected in the subjective ratings. The majority of patients and physicians in the Moroccan and Middle Eastern populations were very satisfied or satisfied with their treatment, in terms of both efficacy and tolerability, and intended to continue on treatment. The ratings were slightly lower in the Moroccan group, but this may have been due to the high rate of missing responses.

In support of our data, a recent systematic review of randomized trials comparing acarbose with other antidiabetic medications concluded that acarbose effectively reduces glycemia when given as both monotherapy and as an add-on to other antidiabetic medication, reverses impaired glucose tolerance, and has a number of beneficial effects with respect to cardiovascular risk. ${ }^{28}$ Likewise, the recent update to the International Diabetes Federation guidelines for management of postmeal glucose ${ }^{29}$ highlights the importance of agents targeting postmeal glucose for reducing vascular events, and the International Diabetes Federation recommends $\alpha$-glucosidases, such as acarbose, as an alternative first-line therapy. ${ }^{30}$

Despite a number of limitations associated with the observational design (including under-reporting of adverse events, treatment bias, alterations in patient behavior, and unknown effects of comedications), these findings indicate that acarbose is effective, accepted, and well tolerated in patients in the Middle East and Morocco, where type 2 diabetes represents a major public health issue. The treatment offers flexibility of use, because it is effective in both monotherapy and combination therapy regimens, in obese patients, and in both pretreated and untreated patients with differing backgrounds of cardiovascular risk factors.

\section{Acknowledgment}

ARS is the guarantor of this manuscript and takes full responsibility for the work as a whole, including the study design, access to data, and the decision to submit and publish the manuscript.

\section{Disclosure}

Editorial assistance was provided by PAREXEL, which was contracted by Bayer, Berlin, Germany. The authors report no conflicts of interest in this work.

\section{References}

1. International Diabetes Federation Atlas. Available from: http://www.idf. org/diabetesatlas/5e/middle-east-and-north-africa. Accessed November $22,2012$.

2. Wild S, Roglic G, Green A, Sicree R, King H. Global prevalence of diabetes: estimates for the year 2000 and projections for 2030. Diabetes Care. 2004;27:1047-1053.

3. Hossain P, Kawar B, El Nahas M. Obesity and diabetes in the developing world: a growing challenge. $N$ Engl J Med. 2007;356:213-215.

4. Khutsoane D, Sharama SK, Almustafa M, et al. Biphasic insulin aspart 30 treatment improved glycaemic control in patients with type 2 diabetes in a clinical practice setting: experience from the PRESENT study. Diabetes Obes Metab. 2008;10:212-222.

5. Reed RL, Revel AD, Carter AO, Saadi HF, Dunn EV. A controlled before-after trial of structured diabetes care in primary health centres in a newly developed country. Int J Qual Health Care. 2005;17:281-286.

6. Belkhadir J, el Ghomari H, Klocker N, Mikou A, Nasciri M, Sabri M. Muslims with non-insulin dependent diabetes fasting during Ramadan: treatment with glibenclamide. BMJ. 1993;307:292-295.

7. DECODE Study Group; the European Diabetes Epidemiology Group. Glucose tolerance and cardiovascular mortality: comparison of fasting and 2-hour diagnostic criteria. Arch Intern Med. 2001;161:397-405.

8. Nakagami T; DECODA Study Group. Hyperglycaemia and mortality from all causes and from cardiovascular disease in 5 populations of Asian origin. Diabetologia. 2004;47:385-394.

9. Hanefeld M, Fischer S, Julius U, et al. Risk factors for myocardial infarction and death in newly detected NIDDM: the Diabetes Intervention Study, 11-year follow-up. Diabetologia. 1996;39:1577-1583.

10. Ceriello A, Hanefeld M, Leiter L, et al. Postprandial glucose regulation and diabetic complications. Arch Intern Med. 2004;164:2090-2095. 
11. Holman RR, Cull CA, Turner RC. A randomized double-blind trial of acarbose in type 2 diabetes shows improved glycemic control over 3 years (UK Prospective Diabetes Study 44). Diabetes Care. 1999;22: 960-964.

12. Lebovitz HE. Alpha-glucosidase inhibitors as agents in the treatment of diabetes. Diabetes Rev. 1998;6:132-145.

13. Van de Laar FA, Lucassen PL, Akkermans RP, van de Lisdonk EH, Rutten GE, van Weel C. Alpha-glucosidase inhibitors for patients with type 2 diabetes: results from a Cochrane systematic review and meta-analysis. Diabetes Care. 2005;28:154-163.

14. Hanefeld M. Cardiovascular benefits and safety profile of acarbose therapy in prediabetes and established type 2 diabetes. Cardiovasc Diabetol. 2007;6:20.

15. Hanefeld M, Cagatay M, Petrowitsch T, Neuser D, Petzinna D, Rupp M. Acarbose reduces the risk for myocardial infarction in type 2 diabetic patients: meta-analysis of seven long-term studies. Eur Heart J. 2004;25:10-16.

16. Rosak C, Haupt E, Walter T, Werner J. The effect of combination treatment with acarbose and glibenclamide on postprandial glucose and insulin profiles: additive blood glucose lowering effect and decreased hypoglycaemia. Diabetes Nutr Metab. 2002;15:143-151.

17. Halimi S, Le Berre MA, Grangé V. Efficacy and safety of acarbose add-on therapy in the treatment of overweight patients with type 2 diabetes inadequately controlled with metformin: a doubleblind, placebo-controlled study. Diabetes Res Clin Pract. 2000;50: 49-56.

18. Li C, Hung YJ, Qamruddin K, Aziz MF, Stein H, Schmidt B. International noninterventional study of acarbose treatment in patients with type 2 diabetes mellitus. Diabetes Res Clin Pract. 2011;92:57-64.

19. Fu AZ, Qiu Y, Radican L, Yin DD, Mavros P. Preexisting cardiovascular diseases and glycemic control in patients with type 2 diabetes mellitus in Europe: a matched cohort study. Cardiovasc Diabetol. 2010;9:15.

20. American Diabetes Association. Standards of medical care in diabetes - 2011. Diabetes Care. 2011;34 Supp1 1:S11-S61.
21. Hara T, Nakamura J, Kon N, Sakakibara F, Takeuchi N, Hotta N. An importance of carbohydrate ingestion for the expression of the effect of alpha-glucosidase inhibition. Diabetes Care. 1996;19:642-645.

22. May C. Wirksamkeit und Verträglichkeit von einschleichend dosierter Acarbose bei Patienten mit nichtinsulinpflichtigem Diabetes mellitus (Typ-II-Diabetes) unter Sulfonylharnstofftherapie. [Efficacy and tolerability of stepwise increasing dosage of acarbose in patients with non-insulin-dependent diabetes mellitus (NIDDM), treated with sulphonylureas]. Diabetes Stoffwechsel. 1995;4:3-8. German.

23. Hollander P. Safety profile of acarbose, an alpha-glucosidase inhibitor. Drugs. 1992;44 Suppl 3:47-53.

24. Mertes G. Safety and efficacy of acarbose in the treatment of type 2 diabetes: data from a 5-year surveillance study. Diabetes Res Clin Pract. 2001;52:193-204

25. Buse J, Hart K, Minasi L. The PROTECT study: final results of a large multicenter postmarketing study in patients with type 2 diabetes. Precose Resolution of Optimal Titration to Enhance Current Therapies. Clin Ther. 1998;20:257-269.

26. Spengler M, Schmitz H, Landen H. Evaluation of the efficacy and tolerability of acarbose in patients with diabetes mellitus: a postmarketing surveillance study. Clin Drug Investig. 2005;25:651-659.

27. Spengler M, Cagatay M. The use of acarbose in the primary-care setting: evaluation of efficacy and tolerability of acarbose by postmarketing surveillance study. Clin Invest Med. 1995;18:325-331.

28. Derosa G, Maffioli P. Efficacy and safety profile evaluation of acarbose alone and in association with other antidiabetic drugs: a systematic review. Clin Ther. 2012;34:1221-1236.

29. International Diabetes Federation. Guideline for the management of postmeal glucose in diabetes. 2011. Available from: http://www.idf.org/ sites/default/files/postmeal\%20glucose $\% 20$ guidelines.pdf. Accessed November 8, 2012.

30. International Diabetes Federation. Treatment algorithm for people with type 2 diabetes. Available from: http://www.idf.org/sites/default/files/Type $\% 20$ 2\%20treatment\%20algorithm.pdf. Accessed November 8, 2012.

\section{Publish your work in this journal}

Diabetes, Metabolic Syndrome and Obesity: Targets and Therapy is an international, peer-reviewed open-access journal committed to the rapid publication of the latest laboratory and clinical findings in the fields of diabetes, metabolic syndrome and obesity research. Original research, review, case reports, hypothesis formation, expert opinion and commentaries are all considered for publication. The manuscript management system is completely online and includes a very quick and fair peer-review system, which is all easy to use. Visit http://www.dovepress.com/testimonials.php to read real quotes from published authors. 